\title{
The Research about Dynamic Relationship between Human and Geography
}

\author{
Hua Liu \\ Scientific Research Institute of Maoming University \\ Guangdong 525000, China \\ Tel: 86-668-292-3175Ｅ-mail: liuhua-5@163.com
}

Fund: Guangdong Province Natural Science Foundation in 2008; Maoming City in 2006 IT projects; Maoming College Natural Science Foundation-funded projects in 2008.

\begin{abstract}
"Human and geographical" is a term short for the relationship between human and geographical environment. Sometimes, it's used to refer to the relationship between human and nature. It is an ever-lasting fundamental relationship, and it is the foundation of all other relations in human society. The process of human using and changing physical geography equals to the evolutive process of the relationship between human and geography. With the social development and the progress of productive forces, this relationship develops and progresses. It is of dynamic character. Nowadays more attention has been paid to the research about the dynamic relationship between human and geography. It marks the progress of society and human's awareness.
\end{abstract}

Keywords: Relationship between human and geography, Dynamic, Research

In the 46 billion year evolvement history of the earth, human came into the world just only 200 million years ago. Since human was born on the earth, there was a relationship between human and geography. It is an ever-lasting fundamental relationship that belongs to the field of the relationship between human and nature, and it is the foundation of all other relations. Human come from the geography environment. In order to exist and multiply human sculpture the geographical environment constantly. The process of human using and changing the physical geography equals to the evolutive process of the relationship between human and geography. With the development of its social development and the progress of productive forces, this relationship develops and progresses. It is of dynamic character. It's not only necessary for the time and the society, but also a sign of social progress and people consciousness's improvement.

\section{The Origin of The Relationship between Human and Geography}

\subsection{The Relationship between Human and Geography is a Kind of Eternal Basic Relations.}

"Human and geographical" is a term short for the relationships between human and geography environment. It specifically refers to the relation between human society and natural environment, which is, an open complex and enormous system is formed through the interaction between human activities and nature environment. From the origin of relation between human and geography, there is geography at first, and then the human follow. Human beings are the product of natural evolution. The geography can exist without human beings, but human beings can not exist without the earth, which means that the relations between human and geography is the relations that human beings depend on geography.

On the occasion of human being come into the world, the relations between human and geography come into existence as a kind of objective relations. It was established with material flow and energy flow as a link. It is an ever-lasting fundamental relationship, which belongs to the field of relationship between human and nature, and it is the foundation of all other relations. Such as the relations of production, blood ties, political relations, economic relations and a series of relations in the course of human society develop, which are all established on the basis of the relationship between human and geography.

\subsection{The Relationship between Human and Geography in the Concept of Geography}

The relationship between human and geography in the concept of geography is different from the general relationship between human and nature. The general relationship between human and nature is a kind of relations between human and the main element of nature, such as the relations between man and air, animals and plants, minerals, mountains, rivers, lakes, oceans and so on. People in the relationship between human and geography of the concept of geography refer to people of the community, people who are engaged in various productive activities or social activities in a certain mode of production, people who exchange material with nature consciously and purposeful and then compose 
society, people who work in a certain geographical space. Geography in the relationship between human and geography of the concept of geography refers to the geographical environment that closely relates to human activities and combines the inorganic and organic nature of various factors in order. The geographical environment exists with geographical differences, whose faces have been changed by human's effect, which includes economic, cultural, social and geographical environment. Human beings are the product of geographical environment. In order to survive and multiply, humans take substances and energy from the environment continuously, and then give back to the environment on the form of waste. In fact, "the human and geography" is an interaction relation between the system of human and geography, with human society constantly enlarging, changing, using, adapting the geography environment, and with the geography environment affecting human activities' geographical character and difference.

\section{The Development of Relationship between Human and Geography}

\subsection{The Relationships between Human and Geography are in an Eternal Developments and Changes.}

The natural environment is in constant, eternal, regular development and changes. Human environment has much more mobility than the natural environment. Therefore, the relationship between human and geography is changing dynamically constantly. This dynamic relationship expresses with different socio-economic and environmental conditions, and the character of relations between human and geography are also in different stages of social development. Human are the main body in the relations between human and geography, and human are the master of geography in the adjusting and controlling system. Not only can they adjust the material and energy exchange between human and geography, but also jump out of the system to intervene and manager the relationship between human and geography purposely and consciously, by planting trees, establishing the protected section of nature, and making all kinds of laws to eliminate the negative impact of natural. Sustainable development is built on the appropriate management and intervention of the population, resources, environment, and economy's high degree of unity; so that human society's long-term development provides sustained economic benefits and environmental benefits. The harmony of the relationship between human and geography is a kind of progress in order, overcoming disorder and chaos. It is the core of sustainable development.

\subsection{The Stage of the Evolutive Relationship between Human and Geography.}

The first stage: human are natural slaves, including the ancient times and agricultural era. (1) Ancient times: from the human naissance (260 million years Quaternary Period) to 20000 years ago, that is the early primitive society. Mankind depends on natural food, living by hunting and gathering, it is no real sense of the production. Since the creation and using of fire, the productivity has a certain level of improvement, but it is still very low in the whole. Human mainly used the nature but did not transform the nature much. On account of human always been threaten by nature, but no ability to conquer the nature, so pay homage to the nature, and pray to God, the cultural totem was born. To survive and fight against nature is the main activity of humans at that time. The environmental problems are the famine caused by excessive and arbitrary picking and hunting. The main solution is migration. (2) The original period of agriculture and animal husbandry: from 20,000 years ago to 200 years ago, that is, New Stone Age primitive society. During the long arduous battle with nature, human learned how to grow plants and domesticated animals, and then entered the original era of agriculture and animal husbandry. Human began the real meaning of production. According to human own needs to produce food, there was the first revolutionary leap, and the production formed the first wave. Human began to transform nature consciously, and tools have a certain progress. "Slash and burn" is the earliest human agriculture technology. Human experienced twice social division of labor that greatly promoted the development of productive forces in this period. However, people's ability to conquer nature is still very limited. Human mainly depend on nature, blessing empyreal pray, worshipping natural as God. Human has been changed from worship totem to saints in concept. They thought that the god dominated the earth. The environmental problem is damaging the geography, including geography erosion and desertification. What deserve our serious consideration is the environmental problems caused by the first wave of production has extended to today, it is still a serious global environmental problems. The solution is relocating in ancient and planting trees in modern.

The second stage: human is the master of nature 200 years ago. On the basis of the continuous development and accumulated of human wisdom ,society have taken place the second revolutionary leaps in the 18th century, making the steam engine widely used for signs of the first technological revolution, rising the second wave of human production. With the rise of industrial civilization, the transition from agricultural society to industrial society provides a rapid development of the productive forces. The second technological revolution makes the wider use of electricity as the mark in the 19th century, increasing labor productivity substantially in a further way, and enhancing the ability of human using and changing natural. Mankind has entered a new industrial age, so that the production activities of the focus from the means of subsistence production to the production of means of production, from manual labor to machine production; from surface resources development to underground resources development, from the use of decentralized renewable energy (wood Grass) to focus on the use of non-renewable fossil fuel energy (coal), from agriculture and animal husbandry (reproductive life) to mining, processing (non-life production); from natural economic 
to the commodity economy. This phase human achieve the numerous technological invention and creation, access to the ability of developing the tremendous natural, making an unprecedented increase of productivity, unprecedented growth in wealth, and a sharp change face of the earth. To dominate nature, conquer nature, and transform nature, human treat themselves as the master of nature. There is a "give me a fulcrum, I can prize the Earth" declaration on the industry.

Under the guidance of ideas "dominate the Earth, people are masters of the earth", all the activities of people around how to plunder the most natural resources and energy to produce the most wealth, for the people to pursue the highest standards and the most whim of the consumer.

The rich material wealth improves the standard of living, resulting in population growth, then, the more the growth of population ,the more needs of production of farm-geography. The rise of the second production wave, people treat the nature as a conquer object, pool, and trash, which caused serious environmental pollution (industrial waste) and ecological damage and have taken place the world-famous eight major pollution incident. Particularly since the 1950s, not only did the industrial waste has large emissions, but also many new sources of pollution and pollutants were emerged, so that now it is difficult to find an unspoiled of "pure geography of Oasis." in the Earth. As a result of industrial pollution greatly exceeded the agricultural pollution, so environmental issues have become the global and the biggest problem which human face.

The third stage: the coordinated development of man and nature

Since 20 century mankind started the third technological revolution, making electronic computers, atomic energy and space technology as the representative of the third wave of the rise of production, so that the human society could go into the information age from the industrial age. Information has become the most important strategic resources, and productive forces have a rapid development. The relationship between human and the environment is more closely. New technology is conducive to deal with the industrial waste and other old environmental issues, but also brought new environment pollution, such as the space junk, nuclear radiation, the white pollution, noise pollution, automobile exhaust, light pollution, electromagnetic pollution and so on, which make the environment problem more complex, more and more serious. People began a serious reflection about the eight major pollution incident caused thousands of deaths in the first half of the 20th century, this is the first time human aware of their living space has been under serious threat, and aware of the urgency and importance to solve environmental problems.

In the 1970s, the Environmental Protection wave came and went, and people began to discuss the major environmental issues, making "environment and development" as the most prominent and most urgent, related to the future survival of the human world Issues after the "War and Peace" in the 20th century. June 3 to 14th in 1992, the delegations from 183 countries and regions, 107 heads of state, 70 representatives of international organizations met in Rio de Janeiro, Brazil, to attend "Environment and Development" the general assembly of the United Nations, and took the sustainable development put forward in 1987 into the "Agenda 21", and then it became the fundamental strategy of human resolving the environment and development issues.

Under the guidance of the sustainable development strategy, human is quietly breeding a global revolution of civilization that is the green revolution using their wisdom to rebuild a new home - eco-home. Therefore, human shouted another slogan "give me a seed, I can dye a Green Earth" in the green civilized era.

In the new century, 60 million people go into a hi-tech, information, environment of the times. Human beings will be developing with the fastest speed, but facing the most serious of the 10 major environmental problems (global warming, ozone depletion, acid rain, air Pollution, depletion and degradation of freshwater resources, solid waste disposal, biodiversity loss, and a sharp drop in forest area, soil degradation and desertification, lack of resources) of the threat. Therefore, only by choosing green and ecological that our common humanity and future generations can humans be in the earth's embrace forever. We must treat the earth as our mother, cherishing her forever.

\section{The Identity of Relationship between Human and Geography}

\subsection{The Basis of Relationship between Human and Geography}

The Earth's surface was in a purely geographical natural state before human's appearing. The natural world started to transform from the natural state to the nature and human interaction since human beings appear. In fact, the whole of mankind's history was the interactions history between human, nature and society. The relationship between human and geography is an ever-lasting basic relation, and it is the foundation of all other relations in human society.

\subsection{The Importance of the Relationship between Human and Geography}

The basis of relationship between human and geography decided its importance further. The coordination of the process between human and geography has always been the important subject which geography focuses on so far. And its main line has been always been around the core of human and geography symbiotic harmony to extend. Therefore, the study about the relationship between human and geography is of great significance whether in the early stages of the 
development of human society, present or future.

\subsection{The Close Relationship between Human and Geography}

Human derived from geographical environment, and sculpture geographical environment constantly. It shaped an inseparable system of human and geography. Human and geography are impacting on each other in this system. Human's activity is subject to geographical environment, but human can dynamic transform and adapt to the geographical environment. Therefore, the natural environment to human society is not the role of control, but effects on human .The adaptation of human to nature geography is not ordinary but dynamic adaptation. Nature is an objective existence, the human have subjective consciousness, and the relationship between the two often changes with the change of the epics. But in any case changes will not affect the close relationship between human and geography until forever.

\subsection{The Dynamic Relationship between Human and Geography}

The relationship between human and geography was emerged with the emergence of human society, developing along with the development of human society. Therefore, the relationship between human and geography is of changing dynamics constantly. In different stages of social development, the human productivity is in different levels, the character of the relationship between human and geography is different too. The dynamic relationship between people and geography was mainly manifested in two aspects: First, the human side, the development of the relations between human and geography mostly depends on the development of human society. With the development of human society, enhancing the level of productivity, the ability of people using and transforming the natural is gradually strengthened. The intake of natural resources is growing, and the scope of developing resources is expanding continuously. Now it is very difficult to find a pure natural virgin geography on Earth. Second, the nature of the party, the development of the relationship between human and geography is based on the increasing reaction of the geographical environment on human. This reaction has not limited to the supply capacity of resources, but also from the living space, quality of life, energy consumption and environment pollution affect the development of human society. The problems such as resource issues, food issues, population issue, energy industry issue, even the world of conflict and peace issues, which were the performances of the relationship between human and geography was deepen.

\subsection{The Contradictions of the Relationship between Human and Geography}

The contradiction is the antithetical site of the relations between human and geography. Human is essentially different from the natural environment. Human essence is the sum total of social relations, with subjective attributes. The life and production of human is subjective, under the control of subjective sense. Human are of psychological, social and cultural composition of intelligence, so it is master of natural. The natural environment is objective, and does not rely on human to exist. It has an objective attribute and its own natural development laws, not transferred by human's will. The objective world's resources are limited, but the human desire is unlimited. In the relations between the people and geography, between the objective attributes and the subjective requirements, the antagonism between the limited resources and the unlimited desires, is the contradictions of relationship between people and geography.

\subsection{The Unity between Human and Geography}

Unity is one side of the relationship between people in the whole side. Human is a part of environment. Human is born in environment and impacting on the environment constantly.

People affect on the environment constantly, which is determined by the social attributes. The process of effect is the process of human using the power of intelligence and consciousness to mobilize the forces of nature for the benefit of mankind, and the process of human using technology to invent advanced tools to affect on nature environment by the labor. As the master of nature environment, human asked for material and energy to protect their own to survive and multiply from the four major atmospheres by the identity of producers. Human created the

Contemporary civilization and made the nature of the community attribute as the consumers human let emissions to the four major atmosphere, polluted the environment , and made the degradation of the world environment. Human and geography formed to be an interrelated and interacted organic whole. As a part of the natural world, human is the biology human, no one can be divorced from nature to exist. The more important thing is the interaction but not only co-existence between human and geography. In addition, the environment is not just the external conditions of human social development. The most important thing is that it is the internal mechanism which people and the environment can develop systematically.

The quality of the environment related to human survival. So, on the one hand the natural decided human, on the other hand human decided the natural. Now these two are intertwined, which means the unity of the objective and subjective. That is, human activities and the laws of nature are unified. Human have to take the initiative to adapt to the object, making the actions in conformity with the objective law. 


\section{Outlook for Relations between People and Geography}

Generally speaking natural evolution process is slow, but human society and economic development are rapid. Human activities impact on natural is fierce, which caused natural changes (evolution or degradation) often exceeds the afford ability of its own evolution, so that led to the rapid transformation of nature. The asymmetry relationship between human and geography indicates that human play a dual role in the relation between human and geography, who are not only the children of the geography, but also the masters of the geography and the initiator of the conflict of human and geography. Therefore, in any era, regardless of the ancient "Harmony" concept, the current theory of sustainable development, or the future "people coexist with geography", a scientific theory of the relation between human and geography has coordination of the two factors.

\subsection{The Ancient "Harmony"}

The so-called "Harmony" is the man and nature combined. It is the basic idea of the ancient Chinese traditional culture. As early as during the Western Zhou Dynasty "Harmony" has been produced, the earlier plain "Harmony" ideology was born after Confucianism, Taoism, and other families' common development. The well-known representatives of "harmony" are the philosophers such as Han Dynasty Dong Zhongshu, the Northern Song Dynasty Zhang Zai and so on. Therefore, "Harmony" can be said to be the master of ancient thought.

Chinese "Harmony" concept was restricted by the level of economic, scientific and technological development., which underlined the interrelated between human and nature. It is necessary to let human in the correctly position of "nature" and to fully understand the law of the "heaven". Therefore, "Harmony" in ancient China can be said that the "theory of sustainable development". Of course, it is only a simple ideas about the relationship between the people and geography, with certain elements of the passive acceptance and helpless. It requires human beings must first of all to conform to "heaven", before they can use the "Heaven." It put forward requests about an appropriate development, protection and conservation of natural resources in order to have sustainable development and use.

\subsection{Today's Sustainable Development}

From 1972's "Human Environment Conference" to the Rio de Janeiro in 1992, "Conference on Environment and Development", marking the awareness of human about the environment and development issues has a qualitative progress, which fully demonstrates human society has established the new ideas of sustainable development. Sustainable development: "human beings have the ability to make development sustainable, and can also guarantee so as to meet the current needs without endangering people's ability to meet their own needs. That is to say, we have to find a road which can make population, economy, society, environment and resource harmonized which can meet the needs of contemporary people and not endanger the needs of future generations.

Sustainable development includes three meanings: First, sustainable development encourages the growth of economic. However, we must change the way of using resources from extensive to intensive, changing the traditional model of economic growth to sustainable development patterns.

Second, sustainable development is based on protecting the natural, with the resources and the environment bearing capacity of coordination. We have to take attention to protect the environment when develop the economy, protecting the renewable resources' indissolubility and the non-renewable resources' limited. We have to try our best to keep the integrity of ecosystem, protect the diversity of organism, and prevent the extinction of biological resources. Third, sustainable development aims at improving the quality of life and adapts to the social progress. The economic growth way which just only simply pursuit the output will destroy the environment, so that the people's quality of life will decline. Clearly, sustainable development is including sustainable economy, sustainable ecology and sustainable society. The sustainable ecology is basis, the sustainable economy is guarantee, and the sustainable society is goal among these three content. The full meaning of sustainable development refers to the beneficial symbiosis and development between human and nature, which is the most scientific knowledge of the relation between human and geography.

Sustainable development has already reached a consensus. It reflects the suspicion and discards about the model of the traditional development, and the yearning of future development

\subsection{The Symbiosis of Human and Geography in the Future}

Science is a knowledge system which accumulated in the course of long-term labor.

Technology is the intermediary and bridge between human and the natural, and an important yardstick of the relation between human and geography. With the increased productivity, scientific and technological progress, the social material wealth and spiritual wealth is growing in the course of human society's development. Therefore, in the future of rapid economic development, highly developed technology, the relationship between human and geography should be based on the sustainable development. In order to make human and geography symbiosis, human have to create favorable conditions for own development, and human ought not to destroy the structure and function of geographical environment for the immediate interests. The symbiosis means the new alliance between human and nature, which is the 
key to the success of sustainable development, especially to such a country likes China who is carrying the world's largest population with grim resources and the environment.

The key and essence of sustainable development are harmonizing and optimizing the relationship between human and geography. The coexistence and development of human and geography are not only the continuation of sustainable development idea, but also the result of the sustainable development.

The realization of human and geographical environment's symbiosis depends on the success of human intervening own actions on human's own initiative. The passive feedback mechanism of geographical environment is formed in a long-term evolution. The human affect on the nature is a very short time compared to the evolution of the geographical environment, but the effect is such profound and strong. Therefore, this demands that we have to prepare in advance on our own initiative, in order to welcome the stages of human and geography coexisting arrival early with ell-developed economy and the intelligence.

\section{References}

He Chengyuan,Wu Shaohong and Yang Qinye. People in the scientific evolution. [J] Soft Science 2004, 18(4): 1-3 .

Ju Naiqi and Ju Yajie.The philosophical reflection on the relationship between man and nature. [J] Journal of College of Arts and Baoji 2008, 28(1): 31-35.

Mao Hanying. To people relations and regional sustainable development. [M]Beijing: China Science and Technology Publishing House, 1995.48-60.

Ou Yanglin . Human relations and progress in theoretical research. [J] Journal of Chifeng College 2008, 24(2): 103-105.

Wu Chuanjun.Geographical relations between the people and the theoretical study and control [J] Journal of Yunnan Normal University 2008, 40(20: 1-3.

Xia Huanlong. The relationship between man and nature in harmony evolution. [J] Shanghai School of Business Journal 2006, 12(1): 8-9.

Zhu Dengchao. To re-examine and establish the relationship between man and nature. [J] Journal of Theory2007, 155(1): 47-48.

Zhu Guohong. On the relationship between people and geography.[J] population and the economy 1995, 88(1): 18-24. 